\title{
Research on Multifunctional Float-assisting, Bulletproof, Puncture-proof Composite Clothes
}

\author{
Xiang-hui Meng ${ }^{1, a^{*}}$, De-de Dai ${ }^{2}$ and Liang Guo ${ }^{3}$ \\ ${ }^{1}$ Troop 91872, Beijing, 102442, China \\ ${ }^{2}$ Ordnance Equipment Department of Naval Equipment Department, Beijing, 100841, China \\ ${ }^{3}$ Shijiazhuang Mechanized Infantry Academy, Shijiazhuang 050083, China \\ amxh0823@163.com
}

Keywords: Multifunctional, Float-assisting, Bulletproof, Puncture-proof.

\begin{abstract}
A soft bulletproof layer is made by utilization of the newest domestic Ultra high molecular weight polyethylene fiber, and by composing float-assisting and puncture-proof functions, multifunctional float-assisting, bulletproof, puncture-proof composite clothes is developed, according to the current flaws of bulletproof clothes such as unique functional and high performance divergence. The clothes comprise a neck protecting body, a coat and a crotch portion protecting body. Two slices of arc-shaped neck guard are protruded in a central round hole which is formed in the neck protecting body. The bottom portion of the neck protecting body is provided with slice-shaped shoulder pads which are taken on shoulder portions. An integrated combination of the shoulder pads and the neck protecting body is formed. Both the inner portion of front slice and the inner portion of the back slice are designed into double-interlayer. A float-assisted layer is placed in an inner interlayer. A bulletproof layer and a puncture-proof layer are placed in an outer interlayer. A lower hem position of the coat is connected with the slice-shaped crotch protecting body. Pockets which are used for inserting bulletproof chest inserting plates and modularization multichannel braids which are used for carrying light equipment are additionally arranged on the front slice of the coat. The modularization float-assisted, bulletproof and puncture-proof clothes are light and handy, practical, reasonable in design and convenient to use and effectively play a safety protection role for personnel engaged in security protection and military missions.
\end{abstract}

\section{Introduction}

To help dealing with many critical situations in the course of duty for security staff, such as protection from attacks from light bullet or stab dagger and so on, researchers invented a variety kinds of bulletproof, puncture-proof cloth preparation techniques ${ }^{[1-4]}$. These inventions can provide better protection for the majority of security personnel and also play a very important role in public safety protection. In 2009, Hou-yong Zhou invented a non-metallic bulletproof and stab-proof cloth, he prepared a multilayer composition nonmetallic stab-proof cloth by composes solidified Kevlar fabric coating epoxy resin and polyamide together with Aramid UD fabric ${ }^{[5]}$. In 2011, Junfeng Ni developed a bulletproof and stab-proof vest which uses multilayer fabric sequentially stacked by PEUD weftless fabric and aramid dipped multilayer woven cloth ${ }^{[6]}$.

According to the analysis about preparation technology and development trend of varied kinds of multifunctional bulletproof and stab-proof cloth, current products can meet the normal requirement for security staff, however, these products are not quite suitable for maritime operations, maritime security tasks executed by special security personnel and so on. As a result, in order to develop multifunctional float-assisting protective garment which comprehensively takes advantages of domestic high-performance protective materials, float-assisting materials and domestic preparation technology with independent intellectual property rights considering the feature of domestic male figure and special safety protection requirement for varied missions such as naval escort, maritime police on duty, fishery enforcement, anti-smuggling and so on, so that the functions such as carriage of individual portable equipment, float-assisting and body protection can be synthesize in one protective cloth by referring to the basic design factors such as structures, materials, and other 
advantages of positive buoyancy bulletproof equipment (bulletproof vests) developed by United States, Russia, Britain and other countries.

\section{Analyses and Determination of Performance Requirement}

Float-assisting Performance. The basic parameters of domestic male figure referred in the research is the average height of 1.73 meter, the average weight of $70 \mathrm{Kg}$, at the same time the weight of supplies and equipment for single soldier is normally less than $13 \mathrm{Kg}$ in view of all kinds of tasks. Given the buoyancy of single soldier and safety margin, the whole protective cloth should offer more than $18 \mathrm{Kg}$ of positive buoyancy to make sure the head of the soldier stay above the water.

Bulletproof Performance. Present mainstream is apt to combined utilization of soft bulletproof layer and removable hard bulletproof boards so that these two kinds of materials can be better arranged in group and the performance of bulletproof. The design for collar protection body, shoulder protection body, neck protection body, crotch portion protecting body, inner core of bulletproof clothing should be in accordance with police standard GA141-2010 II, III and US NIJ0101.04 III, so that the clothing can effectively endure strike from bullets of 92 type pistols, 54 type pistols, 79 type light machine gun and Uzi 9mm light machine gun of USA.

The design of removable hard bulletproof boards is in accordance with GJB4300-2002 VI of China and NIJ0101.04III, NIJ0101.04IV of the USA, as a result the boards can effectively resist $5.8 \mathrm{~mm}$ bullets of 95 type automatic rifle, $5.8 \mathrm{~mm}$ rifle bullets of 97 type rifle, $7.62 \mathrm{~mm}$ bullets of M14 type automatic rifles, $7.62 \times 54 \mathrm{~mm}$ NATO bullets, $7.62 \times 39 \mathrm{~mm}$ rifle bullets of AK47 type assault rifle and armor-piercing bullets of sniper rifles.

Puncture-proof Performance. The cloths should at least be able to resist attack with kinetic energy of 24J, in the light of normal requirement on puncture-proof performance. The results showed that the puncture-proof performance of the cloth is in consistent with Chinese police GA68-2008 standard and US police puncture-proof standards.

\section{Designs and Preparation of Components}

The System and Its Components. The protective cloth has three major components: the coat, modular portable accessories and bulletproof removable boards. The coat is constituted of the cover, puncture-proof layer, soft bulletproof layer and float-assisting layer, etc; the modular portable accessories are designed into several standardized modules to hold varied kinds of portable supplies and equipment; bulletproof removable boards are designed into couples and distinguished as front part and back part which is loaded into corresponding bags on the coat, as shown in Figure 1.
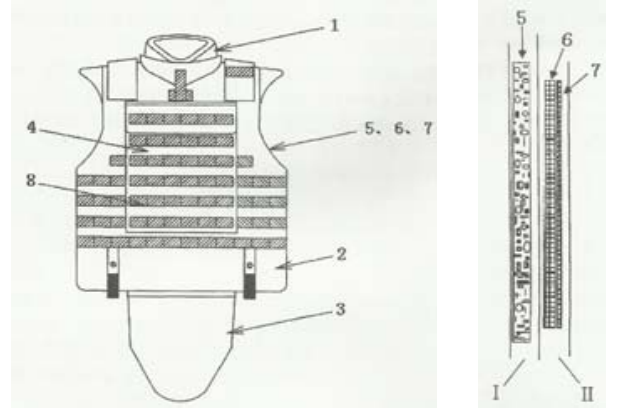

1. Collar protection body, shoulder protection body, neck protection body 2. Cover of coat 3. Crotch portion protecting body 4. Bags of Bulletproof removable boards 5. Buoyancy layer 6.bulletproof layer 7.

Puncture-proof layer 8. Bulletproof removable boards

Fig.1. Structural Sketch map of the coat

Design of the Coat. The material of the coat is polyester fiber Oxford cloth which is waterproof, fire retardant and wear resistant. Considering the convenience command for dressing, requirement for flexible movement, diversified supplies and equipment, adaptability requirement for different waist and height, it's reasonable to design two sections as the front and back of the coat according to the design principles of ergonomic, each section has a double compartment layer to place the soft 
bulletproof layer, puncture-proof layer and buoyancy layer in proper order. The inside lining cloth is black polyester mesh lining sandwich cloth which is beneficial to ventilation and cooling. Outside of each section of the coat, there are pockets with the size of $30 * 25 \mathrm{~cm}^{2}$ designed to hold removable bulletproof boards and multi-channel ribbons suitable to load modular portable light equipment, for example flares, light sticks, communication tools, GPS locator, water bags, multi-purpose radio /equipment packages. Ribbons are also applied on the shoulder and waist outside the coat to fit people with varied height and waist. Crotch portion protecting body is connected to front section of the coat with rough surfaced Velcro, which makes it easy to be disassembled.

Modular Design. The portable accessories, float-assisting layer, bulletproof layer, puncture-proof layer, collar protection body, neck protection body, shoulder protection body, neck protection body and some other parts are designed into modules to form a complete set with the coat and the ribbon system, according to requirement on flexibility for combination of modules and facilitation to unload the cloth.

Portable Accessories. Based on ergonomics principle, modular design principle, combination design principle and analysis of investigation result, the design requirement is determined by inputting overall types of naval missions. Then the category, models, amounts, sizes and weights of more than 10 kinds of accessories are determined, standardized sizes for each module is determined. The position and fasten measures for each module is determined by analysis of human movement characteristics combined with facility requirement for accessing of accessories. The handcuffs box, for example, is designed to place handcuffs or rope. The size of the handcuffs box is $110 \mathrm{~mm}$ (length) * $50 \mathrm{~mm}$ (width) * $150 \mathrm{~mm}$ (height), the whole module is mould pressed with hard PVC, a belt buckle tied the belt with the back of handcuffs box with the size of $50 * 70(\mathrm{~mm})$.

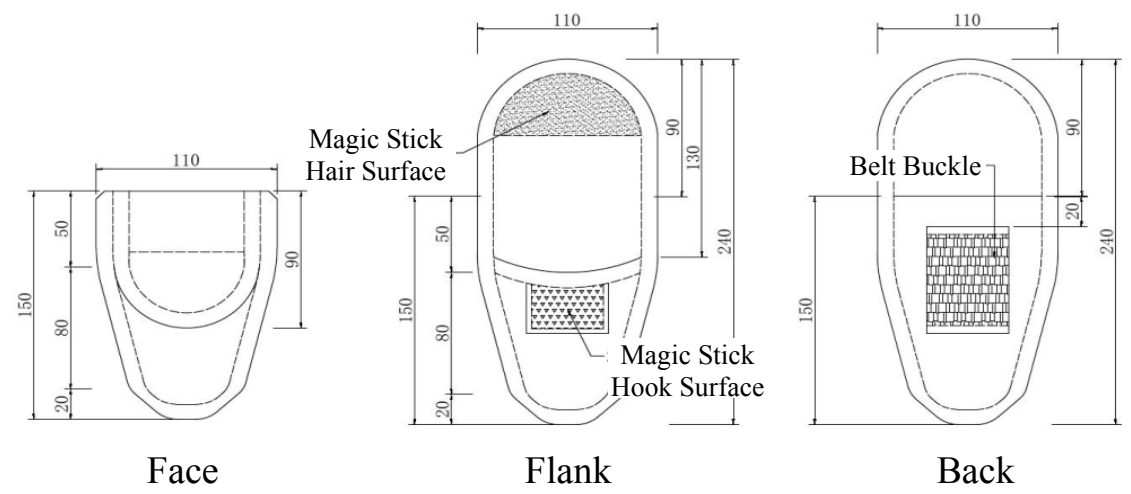

Fig.2. The structure of handcuff box

Float-assisting layer, Bulletproof Layer and Puncture-proof Layer. (1) Float-assisting layer. The standard weight of domestic male is set as $70 \mathrm{~kg}$, as a result the protective cloth should be able to provide positive buoyancy of more than $18 \mathrm{~kg}$ (fresh water). To meet the requirement for positive buoyancy, the domestic high density foam rubber materials (chemical name NBR-PVC, density $65 \mathrm{~kg} / \mathrm{m}^{3}$ ) is chosen as the material for float-assisting layer, and the material is a kind of safe non-toxic light float-assisting materials. The thickness of the layer is $20 \mathrm{~mm}$, the area of front layer $0.208 \mathrm{~m}^{2}$, the area of back layer $0.242 \mathrm{~m}^{2}$. Float-assisting material is sealed with taffeta PVC glue cloth to make sure the float-assisting layer is waterproof and convenient for disassembly and replacement. (2) Bulletproof layer and puncture-proof layer. The soft bulletproof layer can meet requirements which are grade II for bulletproof and grade I for fragment resistant of police standard GA141-2010. The layer is piled up with 40 high modulus polyethylene fibers woven cloth with intellectual property (UHMWPE), its density is $6.8 \mathrm{~kg} / \mathrm{m}^{2}$, which means that it's $10 \%$ lower than requirement of grade II standard GA141-2010, the requirements claimed in assignment book is meet. The overall area of the vest and crotch is larger than $0.28 \mathrm{~m}^{2}$, and the protective sleeve of bulletproof layer is made of heat sealed black opaque nylon taffeta polyester waterproof cloth. 


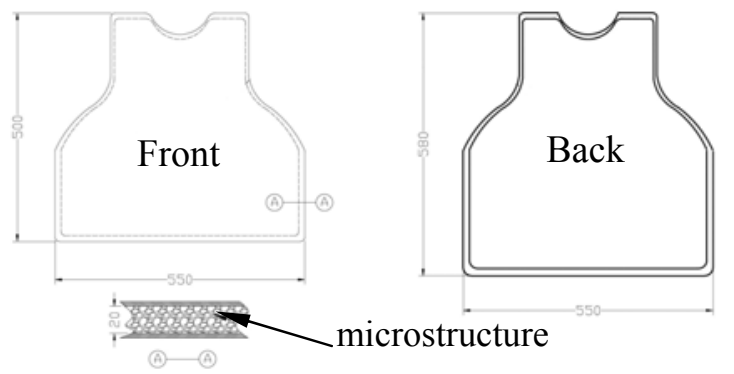

Fig.3. Sketch up for structure of float-assisting layer

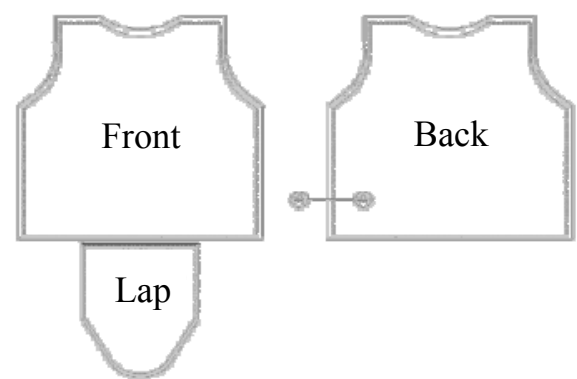

Fig.4. Sketch up for structure of bulletproof layer

Similarly, the material of puncture-proof layer is high performance lightweight aluminum alloy plate, and the lightweight aluminum alloy plate is made into flakes and compounded with high strength fiber canvas, as shown in Figure 4. The coat of the cloth is arranged in a dual compartment, so that when it comes to assembly, the float-assisting layer is loaded into the inner interlayer first, then the bulletproof layer outer interlayer, finally the puncture-proof layer is loaded outside of the bulletproof layer.

Collar Protection Body, Shoulder Protection Body and Neck Protection Body. Collar protection body, shoulder protection body and neck protection body are integrated designed into unitary, the fabric of coat is polyester fiber Oxford cloth which is waterproof, fire retardant and wear resistant, and soft cotton is opted to protect joint of human body. The material of bulletproof layer is double orthogonal super thin soft UD witless cloth $\left(130 \sim 140 \mathrm{~g}\right.$ per $\left.\mathrm{m}^{2}\right)$ made of ultra high molecular weight polyethylene fiber (UHMWPE). Surface density of the layer is $<6.8 \mathrm{~kg} / \mathrm{m}^{2}$, the protection area is $0.1 \sim 0.11\left(\mathrm{~m}^{2}\right)$. All 2 shoulder protection bodies, 1 neck protection body, 2 collar protection bodies and 1 crotch portion protecting body are heat sealed with soft polyester waterproof cloth and then integrated with the coat. These features made the cloth comfortable and flexible for wearing, it can soundly meet the requirements for grade I bulletproof performance and grade II puncture-proof performance according to GA141-2010.

Removable Bulletproof Board. To improve the bulletproof and puncture-proof performance, removable bulletproof boards are designed. Combined utilization of the boards and soft bulletproof layer can meet requirement on bulletproof performance listed in grade VI GJB4300-2002. The radian of the boards is $\mathrm{R} 400$, and its density is $26 \mathrm{~kg} / \mathrm{m}^{2}$, size $300 * 250 \mathrm{~mm}$ (ceramic chip protection layer included), available protection area is $0.07 \mathrm{~m}^{2}$, which is in accordance with GJB5478-2006.

There are two kinds of material applied in the removable bulletproof board: double orthogonal ultra high molecular polyethylene fiber UD weftless cloth is used to laminate the back plate, and the density of the plate is $13.3 \mathrm{~kg} / \mathrm{m}^{2}$; all 79 hexagonal lightweight silicon carbide ceramic plates are selected with thickness of $4.2 \mathrm{~mm}$ and side length of $30 \mathrm{~mm}$.

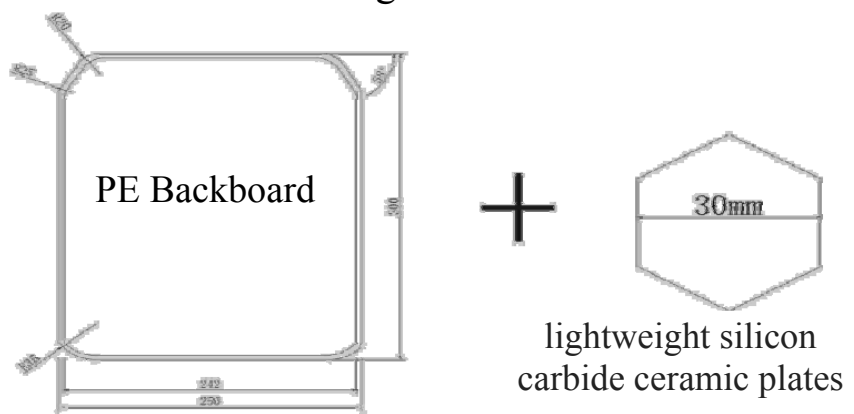

Fig.5. Sketch up for structure of removable bulletproof board

\section{Conclusions}

As shown by the feedback from maritime security stuff and naval escort personnel by utilization in different missions, the protective cloth is designed reasonably, lightweight and practical. The cloth has great float-assisting property and relative larger protection area, it also integrated multiple protection functions such as bulletproof and puncture-proof. The design of standardized module makes it more convenient to adjust the cloth for varied users and missions and 
carry more kinds of supplies and equipment etc. It's the special design that makes the cloth effective, fully functional protection equipment with excellent performance for maritime security personnel and military personnel.

\section{References}

[1] Jie-cai Zhou, Deng-peng Wu, Xiang-zhi Yin, etc. Investigation of present situation and development of bulletproof and puncture-proof cloth [J]. Jiangsu Weave, 2011 (12) 40-43.

[2] Xian-chong Huang. Research of bulletproof and puncture-proof material and its development trend [J]. Weave Herald, 2013 (1) 87-91.

[3] Yi Qu, Bin Wang, Qiao-li Qin, etc. Technology of bulletproof and puncture-proof cloth and its development trend [J]. Chinese Security \& Surveillance, 2013 (7) 55-59.

[4] Xin-ling Fang, Hao Chang, Dongmei Xu, etc. Research on bulletproof and puncture-proof performance of Aramid UD fabric [J]. High-tech Fabric and the Appliance, 2015 (3) 45-48.

[5] Hou-yong Zhou. Non-metallic shellproof and puncture-proof armor, China, Patent 201,577,565. (2009)

[6] Jun-feng Ni. Bulletproof and stabproof vest, China, Patent 2022,768,469. (2011) 